\title{
Subsidization Versus Cooperation as Incentive for Emission Reduction R\&D in a Supply Chain
}

\author{
Qinqin $\mathrm{Li}^{*}$ \\ School of Marketing and Logistic Management,Nanjing University of Finance and Economics, \\ Nanjing 210023, China; baoyan209@163.com \\ *Correspondence: baoyan209@163.com
}

\begin{abstract}
This paper studies the emission reduction R\&D in a two-level supply chain under two technology policies: R\&D subsidization and $R \& D$ cooperation, and compares the performance of the two technology policies. By means of game theory, we derive the equilibrium decisions and then compare optimal decisions, profits and social welfare under the two policies with exogenous tax. Our results indicate that production quantity andemissions under $R \& D$ subsidization policy are lower than those under $R \& D$ cooperation policy, while the effort of the R\&D subsidization policyis higher thanthat of the R\&D cooperation policy. In addition, we identify the conditions when the $R \& D$ subsidization policy performs better thanthe $R \& D$ cooperation policy, and find that the comparison results thatsupply chain profits and social welfare depend on the level of emissions tax, the efficiency of R\&D technology and the steepness of marginal environmental damage function. In most cases, $R \& D$ cooperation policy leads to higher social welfare compared with R\&D subsidization policy.
\end{abstract}

Keywords-Game theory; Carbon emissions; R\&D; Technology policy

\section{INTRODUCTION}

With the increase of consumer awareness of environmental protection and the pressure from government and regulations, more and more firms are trying to produce more environment-friendly products and reduce thecarbon emissionsin production by investing in $R \& D$ technologies. For example, Siemens and Haier have taken actions to reduce carbon emissions(Wang et al., 2016), and Volvo group has implemented the environment improvement strategy, such as improving its fuel efficiency and adopting renewable energy, so as to reduce the carbon emissions from production process.

In order to encourage firms to reduce their negative impact of carbon emissions on the environment, government regulators have taken some actions, for example, the carbon emission tax has beenimplemented in Sweden and Australia. Insome countries, technology policies have been implemented to stimulate firmR\&Defforts, profits and social welfare, such as tax incentive schemes, $R \& D$ subsidies and encouragement of R\&D cooperation. Those technology policies operate in different ways to induce R\&D activities.Bycontrolling emission trading price and providingtechnology investment subsidies, the government can induce the firms to invest in emissionreduction R\&D technologies(Lou et al., 2015). Here we explore the conditions when $\mathrm{R} \& \mathrm{D}$ subsidization performs better (worse) than encouragement of $R \& D$ cooperation in a supplier-manufacturer supply chain.
R\&D subsidization policy has received considerable attentions and is regarded as an effective way to stimulate more R\&D efforts(Ben Youssef, and Zaccour, 2014; Haaland, and Kind, 2008; Toivanen, 2006). Spencer, and Brander (1983) presented a theory of government intervention which provides an explanation for industrial strategy policy such as R\&D or export subsidies in imperfectly competitive international markets. Fan, and Wolfstetter (2006) reconsidered the explanation of R\&D subsidies by Spencer, and Brander (1983) They enriched their model by allowing firms to pool R\&D investments and licensed the innovation of the RJV. Dakhlia et al. (2004) studied duplication of R\&D and R\&D subsidies and showed that the presumed incompatibility of uncoordinated $\mathrm{R} \& \mathrm{D}$ and competition is not fundamental, but hinges on the nature of R\&D spillovers. Haaland, and Kind (2006) and Haaland, and Kind (2008) compared cooperative and non-cooperative $\mathrm{R} \& \mathrm{D}$ subsidy policies and focused on product differentiation and trade costs. Gretz et al. (2009) considered the optimal R\&D subsidy regime in a two-firm two-country model. Shin, and Kim (2010) analyzed the effect of government subsidy policies on creating an incentive for domestic firms to improve their product quality before exporting to an outside market. Gretz et al. (2012) investigated government subsidy games for private sector $R \& D$ in a two-country two-firm intra-industry trade model and compared two funding structures: cost sharing and reward for performance.Ouchida, and Goto (2014)reexamined the model proposed by Poyago-Theotoky anddiscussed how negative emission taxes affect the emission reduction behavior. Lu, and Shao (2016) investigated how the government subsidies influence the pricing and performance level decisions in Energy Performance Contracting (EPC) and showed that government subsidies can improve the performance levels of EPC as well as the firms'profit.Liu et al. (2017) discussed the effect of taxations and subsidies imposed by the government on electric vehicleindustry development based on evolutionary game and find that there is no evolutionary stale strategy between manufacturers and government. In contrast to Liu, Huang, and Yang (2017), in our study, we investigate whether the government should give the manufacturer subsidies or encourage the retailer to cooperate with the manufacturer to attain social welfare maximization. The above literature focus on the comparison of the effect of different government policies, however, they do not consider the cooperation mechanism of supply chain members.

Starting with D'Aspremont, and Jacquemin (1988), a large number of literature has emerged to formalize firm's 
incentives to engage in horizontal R\&D cooperation (Inkmann, 2000; Suetens, 2005; Suzumura, 1992). They showed that $\mathrm{R} \& \mathrm{D}$ cooperation is the optimal decision in a duopoly model.Atallah (2004) explored the effect of information sharing on non-cooperative $R \& D$, the complementarity between cooperative $\mathrm{R} \& \mathrm{D}$ and non-cooperative $\mathrm{R} \& \mathrm{D}$. On the other hand, a parallel stream of literature, represented by Ishii (2004), focused on vertical R\&D cooperation by the players in a two-level supply chain. Ishii (2004) analyzed the effects of cooperative $R \& D$ and compared four vertical $R \& D$ organization modes: non-cooperative $R \& D$, vertical R\&D cartels, vertical non-cooperative RJVs and vertical RJV cartels intwo competitive two-level supply chains. Inkmann (2000) analyzed horizontal R\&D cooperation by incorporating vertical $R \& D$ cooperation between upstream and downstream firms into the usual two-stage oligopoly models and found that vertical $R \& D$ cooperation usually maximizes the profits of the participating firms.Ge et al. (2013) discussed firms' R\&D cooperation behavior in a supply chain with considering spillovers and found out the condition in which firms can achieve win-win situation. The above two technology policies, $R \& D$ subsidization and $R \& D$ cooperation, have been proved to be effective to promote $R \& D$ activities, yet the question which policy is more effective is not examined in the above literature. They only investigated the effectiveness between R\&D subsidies and R\&D without subsidies, or between cooperative $R \& D$ and non-cooperative $R \& D$.

In the industrial-organization literature, some papers have compared the performance of the two technology policies in a duopoly model.Hinloopen (1997) compared the effect on private $R \& D$ investments of allowing firms to cooperate in R\&D with that of providing $R \& D$ subsidies and found that in general the latter policy is more effective than the former in promoting R\&D activity.Further,Hinloopen (2001)compared non-cooperative $R \& D$ subsidies with allowing cooperative $\mathrm{R} \& \mathrm{D}$ and showed that providing $\mathrm{R} \& \mathrm{D}$ subsidies is more effective in raising private $R \& D$ investments than sustaining R\&D cooperatives.Petrakis, and Poyago - Theotoky (2002) analyzed and compared the cases where technology policy takes the form of $R \& D$ subsidization or $R \& D$ cooperation in a duopoly with spillovers and pollution in terms of welfare. They found that the comparison of social welfare in the two different technology policy set-ups hinge on the relative magnitude of the spillover rate and the steepness of the marginal environmental damage function. Furthermore, Poyago-Theotoky (2007) considered a setting where the regulator or government possesses limited commitment power and addressed the question of the importance of the organization of environmental $\mathrm{R} \& \mathrm{D}$ in relation to emission reduction and associated social welfare. They showed that environmental $R \& D$ is higher in the case of an environmental R\&D cartel compared to independent R\&D. Ouchida, and Goto (2014) reexamined the Poyago-Theotoky model and provided additional investigation, which was conducted under a corrected environmental damage parameter. As reviewed above, even though the existing literature has examined the social welfare under the two technology policies: R\&D subsidizationand R\&D cooperation in a duopoly model, how thetwo technology policies affect the emission reduction R\&D in a supplychain is not yet fully known. In addition, it is important to know which technology policy performs better. To the best of our knowledge, the above important research issueshave not yet been explored in the literature. Addressing these research questionshence outlines the contribution of this paper.

In this paper, we consider a two-level supply chain, in which the supplier generates pollutions in its produce process and has to pay tax for the emissions. The supplier can reduce its tax burden by undertaking $\mathrm{R} \& \mathrm{D}$ effort to reduce its emission. In this setting, we will study the emission reduction R\&D under two technology policies: R\&D subsidization and $R \& D$ cooperation, and compare the performance of the two technology policies. By means of game theory, we derive the equilibrium decisions and then compare the optimal decisions, profits and social welfare under the two policies with exogenous tax.

In our study, weidentify the conditions when the R\&D subsidization policy performs better than the policy of encouraging $R \& D$ cooperation. Our results indicate that the production quantity and the emissions under the R\&D subsidization policy are lower than those under the R\&D cooperation policy, while the $R \& D$ effort is higher than $R \& D$ cooperation policy. In addition, the comparison results of supply chain profits and social welfare depend on the level of emissions tax, the efficiency of the R\&D technology and the steepness of the marginal environmental damage function. For a relatively wide class of cases, $R \& D$ cooperation policy leads to higher social welfare compared with $R \& D$ subsidization policy.

This paper is organized as follows. In Section 2 the model is presentedand in the Subsections the equilibrium decisions of the two cases: $R \& D$ subsidization and $R \& D$ cooperation, are analyzed. We make somecomparisons between the two technology policies in Section 3. Section 4concludes the paper with possible future research directions.

\section{MODEL DESCRIPTION}

In our study, we consider a two-echelon supply chainconsisting of one supplier and one manufacturer. The supplier generates pollutions in its produce process and has to pay tax for the emissions. By undertaking $R \& D$ effort to reduce its emission, the supplier can reduce its tax burden. We study the emission reduction R\&D of the supplier under two technology policies: R\&D subsidization and $R \& D$ cooperation, and compare the performance of the two technology policies.

We have the following notations:

$a$ themarket potential;

$c$ theunit production cost of the supplier, $a \geq c>0$;

${ }^{t}$ the emissions tax;

$x$ theemission reduction $\mathrm{R} \& D$ Devel;

$w$ thewholesale price of the raw material;

$r$ the efficiency of the R\&D technology;

$d$ the steepness of the damage function; 
$S$ the proportion of $\mathrm{R} \& \mathrm{D}$ costs undertaken by the government.

We consider a two-echelon supply chain consisting of one supplier and one manufacturer. Similar to the prior literature(Banerjee, and Lin, 2001; D'Aspremont, and Jacquemin, 1988; Hinloopen, 1997), we consider a linear demand, $p=a-q$, where $a$ is the market size. In the production process, the supplier generates pollution, which is taxed at the rate $t$ on emission. The emissions tax is exogenous. The supplier can reduce its tax burden by undertaking $\mathrm{R} \& \mathrm{D}$ effort, $x$, to reduce its emission. The $\mathrm{R} \& \mathrm{D}$ effort cost is $r x^{2} / 2$, which assures that the profit function is concave on $x$, i.e., reducing emissions has a decreasing return. $r$ captures the efficiency of the R\&D technology and $r>0$. Each unit of output generates one unit of pollution, thus, we express the supplier's emissions as $e=q-x$. The damage function is assumed to be quadratic in aggregate emissions, $D=d(q-x)^{2} / 2$, where $d$ is the steepness of the damage function.

To maintain analytical tractability, we don't consider the manufacturer's marginal cost. We compare two different models with respect to $R \& D$ for emissions reduction: $R \& D$ subsidization and R\&D cooperation. In the first model, the R\&D costs of the supplier are subsidized by the government who moves first to set the subsidy rate. Next, the supplier determines the wholesale price and R\&D effort. Finally, the manufacturer decides the quantity of the products. In the second model, there are no R\&D subsidies but the supplier and manufacturer cooperate in determining their R\&D effort and quantity in order to maximize the total profits. In the following, by means of game theory, we derive the equilibrium decisions of both the models and then compare the optimal decisions, profits and social welfare under the two policies with exogenous tax.

\section{A. R\&Dsubsidization}

In this section, the government provides subsidies for the emission-reducing $R \& D$ costs but without $R \& D$ cooperation permit. The $R \& D$ costs undertaken by the government is $s \cdot \frac{1}{2} r x^{2}$ and the left, $(1-s) \cdot \frac{1}{2} r x^{2}$, is undertaken by the supplier. Therefore, the profit of the supplier and the profit of the manufacturer are as follows:

$$
\begin{array}{r}
\pi_{s}=(w-c) q-t(q-x)-(1-s) \cdot \frac{1}{2} r x^{2} \\
\pi_{m}=(a-q-w) q(2)
\end{array}
$$

In order to determine the equilibrium by backward induction, we first solve the manufacturer's optimal quantity. Solving the first order condition of Eq. (2), we find that the optimal quantity is

$$
q^{s}=\frac{a-w}{2}(3)
$$

Using the Eq. (3), we can derive the supplier's profit shown in Eq. (4).

$$
\pi_{s}=\frac{(w-c)(a-w)}{2}-t\left(\frac{a-w}{2}-x\right)-(1-s) \frac{1}{2} r x^{2}
$$

Solving the first order condition of Eq. (4) with respect to $w$ and $x$, we find that the optimal wholesale price and R\&D effort are

$$
\begin{aligned}
& w^{s}=\frac{a+c+t}{2} \\
& x^{s}=\frac{t}{r(1-s)}
\end{aligned}
$$

Inserting Eq. (5) into Eq. (3), we obtain

$$
q^{s^{*}}=\frac{a-c-\mathrm{t}}{4}
$$

In the first stage, the government determines the optimal rate of subsidy to maximize social welfare. The social welfare is as follows:

$$
W=\frac{1}{2} q_{m}^{2}+\pi_{s}+\pi_{m}-s \cdot \frac{1}{2} r x^{2}-\frac{d}{2}(q-x)^{2}
$$

Solving the first order condition of Eq. (8), we find that the optimal rate of subsidy is

$$
s^{*}=\frac{d r(a-c-t)-4 t(d+r)}{d r(a-c-t)}
$$

Inserting Eq. (9) into Eq. (6), we obtainthe optimal R\&D effort

$$
x^{s^{*}}=\frac{d(a-c-t)}{4(r-d)}
$$

Proposition 1. In the case of R\&D subsidization, the optimal wholesale price, $R \& D$ effort, quantity andsubsidy rate are respectively

$$
\begin{gathered}
w^{s^{*}}=\frac{a+c+t}{2} \quad x^{s^{*}}=\frac{d(a-c-t)}{4(r-d)} \quad, \quad q^{s^{*}}=\frac{a-c-t}{4}, \\
s^{*}=\frac{d r(a-c-t)-4 t(d+r)}{d r(a-c-t)},
\end{gathered}
$$

From Proposition 1, we find that, in the R\&D subsidization case, the R\&D effort decreases with the increase of emissions $\operatorname{tax}, t$, but increases with the slope of the marginal damage function, $d$. 


\section{B. $R \& D$ cooperation}

In this section, the government encourages the emission-reducing $\mathrm{R} \& \mathrm{D}$ by permitting the firms to cooperate in a centralized supply chain. In this model, the supplier and the manufacturer cooperatively set their R\&D and quantity in order to maximize their total profits. The total profits of the supplier and manufacturer are as follows:

$$
\pi_{c}=(a-q-c) q-t(q-x)-\frac{1}{2} r x^{2}
$$

Solving the first order condition of Eq. (15), we derive the optimal quantity and R\&D as follows.

Proposition 2. In the R\&D cooperation model, the optimal quantity and $R \& D$ are

$$
q^{c^{*}}=\frac{a-c-t}{2}, x^{c^{*}}=\frac{t}{r}
$$

From the equitations above, we can derive the profit of the supply chain and the social welfare. Additionally, we find that the $R \& D$ effort in $R \& D$ cooperation case increases with the emissions tax but decreases with the efficiency of the R\&D technology. In addition, the R\&D effort is not related to the slope of the marginal damage function, $d$, which is different from the case of $R \& D$ subsidization.

\section{A COMPARISON: R\&D SUBSIDIZATION VERSUS R\&D COOPERATION}

In this section, we compare the optimal quantity, $R \& D$ effort, emissions, the supply chain profit and social welfare of the two models: R\&D subsidization versus $R \& D$ cooperation. For the ease of analysis, we summarize the results in Table 1.

Table 1. Summary of the equilibrium decisions under the two technology policies

\begin{tabular}{ccc}
\hline $\begin{array}{c}\text { The } \\
\text { optimal values }\end{array}$ & $\begin{array}{c}\text { R\&D } \\
\text { subsidization }\end{array}$ & $\begin{array}{c}\text { R\&D } \\
\text { cooperation }\end{array}$ \\
quantity & $\frac{a-c-t}{4}$ & $\frac{a-c-t}{2}$ \\
$\begin{array}{c}\text { R\&D } \\
\text { effort }\end{array}$ & $\frac{d(a-c-t)}{4(r-d)}$ & $\frac{t}{r}$
\end{tabular}

It is easy to find that $q^{s^{*}}<q^{c^{*}}$.

(2) R\&D effort

Since $x^{s}=\frac{t}{r(1-s)}$, shown in Eq. (6), and $0<s<1$, we have $x^{s^{*}}-x^{c^{*}}>0$.

Suppose that there is no emission tax in operation, i.e. $t=0$. In this case the supplier will not conduct any $\mathrm{R} \& \mathrm{D}$ effort, which is not discussed in this paper. Therefore, we consider an exogenous emissions tax in the followingand $t>0$.

From the analysis above, we obtain the following proposition.

Proposition 3. The quantity is lower in R\&D subsidization model than in $R \& D$ cooperation model, while the R\&D effort is higher in $\mathrm{R} \& \mathrm{D}$ subsidization model than in $\mathrm{R} \& \mathrm{D}$ cooperation model.

(3) Emissions

Since $q^{s^{*}}<q^{c^{*}}$ and $x^{s^{*}}>x^{c^{*}}$, we have $q^{s^{*}}-x^{s^{*}}<q^{c^{*}}-x^{c^{*}}$.

Corollary 1 . The emissions in R\&D subsidization model are lower than in R\&D cooperation model.

Corollary 2. The emissions tax in R\&D subsidization model is lower than in R\&D cooperation model.

(4) The supply chain profit

In the case of an exogenous emissions tax, $t>0$, we can obtain the following proposition.

Proposition 4.

(i) When $d^{2} r^{2}-16 d r^{2}-8 d^{2} r-8 r^{3}>0$, there are three cases depending on the value of the exogenous emissions tax relative to two critical level, $t_{1}$ and $t_{2}$, which is given by

(1) Quantity

$$
\begin{gathered}
t_{1}=\left[\left(r^{2}+2 d r-\sqrt{d^{2} r^{2}-16 d r^{2}-8 d^{2} r-8 r^{3}}\right)(a-c)\right] /\left(r^{2}+8 d+3 d r+8 r\right) \\
t_{2}=\left[\left(r^{2}+2 d r+\sqrt{d^{2} r^{2}-16 d r^{2}-8 d^{2} r-8 r^{3}}\right)(a-c)\right] /\left(r^{2}+8 d+3 d r+8 r\right)
\end{gathered}
$$

. (a) Such that for $t<t_{1}$ and $t>t_{2}$ the supply chain profit in $R \& D$ subsidies model is higher than in $R \& D$ cooperation model, (b) for $t_{1}<t<t_{2}$ the supply chain profit in R\&D subsidies model is lower than in R\&D cooperation model and (c) the supply chain profit in R\&D subsidies model is equal to that of $\mathrm{R} \& \mathrm{D}$ cooperation model when $t=t_{1}$ or $t=t_{2}$. (ii) When $d^{2} r^{2}-16 d r^{2}-8 d^{2} r-8 r^{3}<0$, for all values of emissions tax, the supply chain profit in $R \& D$ subsidization model is higher than in R\&D cooperation model.

Proposition 4 identifies conditions on the efficiency of the $\mathrm{R} \& \mathrm{D}$ technology, $r$, and the slope of the marginal damage function, $d$, such that the supply chain profit in R\&D subsidization model is higher (lower) than the supply chain profit in $\mathrm{R} \& \mathrm{D}$ cooperation model. When 
$d^{2} r^{2}-16 d r^{2}-8 d^{2} r-8 r^{3}>0$, in the case where the emissions tax is set at a relatively low level or a relatively high level, the supply chain can obtain higher total channel profit in the case of $R \& D$ subsidization than that of $R \& D$ cooperation. In addition, where the emissions tax is set at a moderate level, the supply chain can obtain higher total channel profit in the case of $\mathrm{R} \& \mathrm{D}$ cooperation than that of $\mathrm{R} \& \mathrm{D}$ subsidization. In the opposite case when $d^{2} r^{2}-16 d r^{2}-8 d^{2} r-8 r^{3}<0$, for all values of emissions tax, the supply chain profit in $R \& D$ subsidization model is higher than in R\&D cooperation model.

\section{(5) Social welfare}

In the case of an exogenous emissions tax, $t>0$, we can obtain the following proposition about comparison of social welfare.

Proposition 5. There are three cases depending on the value of the exogenous emissions tax relative to two critical level,

$$
\begin{aligned}
& t_{3} \text { and } t_{4}, \quad \text { which is given by } \\
& t_{3}=\frac{\left[4 d^{2}(2+r)+d r(7+3 r)-r^{2}-4(r+d)^{3} \sqrt{(r+5)(r+d)}\right] r(a-c)}{r^{2}\left(3 r+19 d+16+3 r d+4 d^{2}\right)+16 d(d r+d+2 r)} \\
& t_{4}=\frac{\left[4 d^{2}(2+r)+d r(7+3 r)-r^{2}+4(r+d)^{3} \sqrt{(r+5)(r+d)}\right] r(a-c)}{r^{2}\left(3 r+19 d+16+3 r d+4 d^{2}\right)+16 d(d r+d+2 r)}
\end{aligned}
$$

(i) Such that for $t<t_{3}$ and $t>t_{4}$ the social welfare in $R \& D$ subsidization model is lower than welfare in $R \& D$ cooperation model.

(ii) For $t_{3}<t<t_{4}$ the social welfare in $\mathrm{R} \& \mathrm{D}$ subsidization model is higher than welfare in $R \& D$ cooperation model.

(iii) In addition, the social welfare in R\&D subsidization model is equal to that of $\mathrm{R} \& \mathrm{D}$ cooperation model when $t=t_{3}$ or $t=t_{4}$.

Proposition 5 identifies conditions that the social welfare in R\&D subsidization model is higher (lower) than the supply chain profit in R\&D cooperation model for different emissions tax level. When the emissions tax is set at a relatively low level or a relatively high level, R\&D subsidization leads to lower social welfare than the encouragement of $R \& D$ cooperation. When the emissions tax is set at a moderate level, R\&D subsidization leads to higher social welfare than the encouragement of $\mathrm{R} \& \mathrm{D}$ cooperation. In order to partially correct for the environmental externality, for the R\&D subsidization setting, the government can impose an emissions tax or properly adjust the rate of the R\&D subsidies. However, for the R\&D cooperation setting, the government can only adjust the emissions tax.

\section{CONCLUSION}

In this paper, we have studied the impact of two technology policies: the R\&D subsidization policy and the policy of encouraging $R \& D$ cooperation on the emission reduction $R \& D$ in a supply chain. We have identified the conditions when the R\&D subsidization policy performs better than the policy of encouraging $\mathrm{R} \& \mathrm{D}$ cooperation by comparing the social welfare of the two technology policies. By means of game theory, we derivethe equilibrium decisions and then comparethe optimal decisions, profits and social welfare under the two policies with exogenous tax. We find that under the R\&D subsidization policy, both the quantity and the emissions are lower than the R\&D cooperation, while the R\&D effort is higher compared to R\&D cooperation. In addition, the comparison results of supply chain profits and social welfare depend on the level of emissions tax, the efficiency of the R\&D technology and the steepness of the marginal environmental damage function. For a relatively wide class of cases, $R \& D$ cooperation policy leads to higher social welfare compared to $\mathrm{R} \& \mathrm{D}$ subsidization.

While our paper makes contributions to the literature regarding supply chain management by investigating the incentive for emission reduction R\&D in a supply chain, there are also some limitations. First, the demand function employed by our model is linear, the demand in practice is much more complex. We will further discuss the problems with non-linear demandand take the consumer environment awareness into account. Second, the information is assumed to be symmetric.It is probably that some parameters are the firms' private information. Hence, another possible extendedstudy is to examine the case of information asymmetry.Third, the supply chain involves in lots of members, investigating a channel systemcomposed of one single manufacturer and several competing retailers or a channelsystemcomposed of several competing manufacturers and one retailer will be interesting. 


\section{REFERENCES}

[1] Atallah, G. (2004) 'The allocation of resources to cooperative and noncooperative R\&D', Australian Economic Papers, Vol. 43 No. 4, pp. 435-447.

[2] Banerjee, S. and P. Lin (2001) 'Vertical research joint ventures', International Journal of Industrial Organization, Vol. 19 No. 1-2, pp. 285-302.

[3] Ben Youssef, S. and G. Zaccour (2014) 'Absorptive Capacity, R\&D Spillovers, Emissions Taxes and R\&D Subsidies', Strategic Behavior and the Environment, Vol. 4 No. 1, pp. 41-58.

[4] D'Aspremont, C. and A. Jacquemin (1988) 'Cooperative and noncooperative $\mathrm{R} \& \mathrm{D}$ in duopoly with spillovers', The American Economic Review, pp. 1133-1137.

[5] Dakhlia, S., et al. (2004) 'A note on duplication of R\&D and R\&D subsidies', Economics Bulletin, Vol. 12 No. 7, pp. 1-5.

[6] Fan, C. and E.G. Wolfstetter (2006) 'Research Joint Ventures, Optimal Licensing, and the R\&D Subsidy Policy', The BE Journal of Theoretical Economics, Vol. 8 No. 1, pp. 1-19.

[7] Ge, Z., et al. (2013) 'Firms' R\&D Cooperation Behavior in a Supply Chain', Production And Operations Management,

[8] Gretz, R.T., et al. (2009) 'Strategic research and development policy: societal objectives and the corporate welfare argument', Contemporary Economic Policy, Vol. 27 No. 1, pp. 28-45.

[9] Gretz, R.T., et al. (2012) 'R\&D subsidy games: a cost sharing approach vs. reward for performance', The Journal of Technology Transfer, Vol. 37 No. 4, pp. 385-403.

[10] Haaland, J. and H.J. Kind (2006) 'Cooperative and non-cooperative R\&D policy in an economic union', Review of World Economics, Vol. 142 No. 4, pp. 720-745.

[11] Haaland, J.I. and H.J. Kind (2008) 'R\&D policies, trade and process innovation', Journal of International Economics, Vol. 74 No. 1, pp. 170-187.

[12] Hinloopen, J. (1997) 'Subsidizing cooperative and noncooperative R\&D in duopoly with spillovers', Journal of Economics, Vol. 66 No. 2, pp. 151-175.

[13] Hinloopen, J. (2001) 'Subsidizing R\&D Cooperatives', De Economist, Vol. 149 No. 3, pp. 313-345.

[14] Inkmann, J. (2000) ' Horizontal and vertical R\&D cooperation', Working paper, University of Konstanz, Germany.

[15] Ishii, A. (2004) 'Cooperative R\&D between vertically related firms with spillovers', International Journal of Industrial Organization, Vol. 22 No. 8, pp. 1213-1235.

[16] Liu, C., et al. (2017) 'The evolutionary dynamics of China's electric vehicle industry - Taxes vs. subsidies', Computers \& Industrial Engineering, Vol. 113, pp. 103-122.

[17] Lou, G.X., et al. (2015) 'Investment Strategy of Emission-Reduction Technology in a Supply Chain', Sustainability, Vol. 7 No. 8, pp. 10684-10708.

[18] Lu, Z. and S. Shao (2016) 'Impacts of government subsidies on pricing and performance level choice in Energy Performance Contracting: A two-step optimal decision model', Applied Energy, Vol. 184, pp. 1176-1183. 